\title{
Article \\ Acquired Comorbidities in Adults with Congenital Heart Disease: An Analysis of the German National Register for Congenital Heart Defects
}

\author{
Susanne J. Maurer ${ }^{1}$, Ulrike M. M. Bauer ${ }^{2}$, Helmut Baumgartner ${ }^{3}$, Anselm Uebing ${ }^{4} \mathbb{D}$, Claudia Walther $^{5}$ and \\ Oktay Tutarel ${ }^{6,7, *}$
}

1 Department of Electrophysiology, German Heart Centre Munich, TUM School of Medicine-Technical University of Munich, 80636 Munich, Germany; susanne.maurer@tum.de

2 National Register for Congenital Heart Defects, Competence Network for Congenital Heart Defects, 13353 Berlin, Germany; ubauer@kompetenznetz-ahf.de

3 Department of Cardiology III-Adult Congenital and Valvular Heart Disease, University Hospital Muenster, Albert-Schweitzer Campus 1, 48149 Muenster, Germany; Helmut.Baumgartner@ukmuenster.de

4 Department of Congenital Heart Disease and Pediatric Cardiology, University Hospital Schleswig-Holstein, 24105 Kiel, Germany; anselm.uebing@uksh.de

5 Department of Cardiology, University of Frankfurt, 60590 Frankfurt am Main, Germany; Claudia.Walther@kgu.de

6 Department of Congenital Heart Disease and Paediatric Cardiology, German Heart Centre Munich, TUM School of Medicine-Technical University of Munich, 80636 Munich, Germany

7 DZHK (German Centre for Cardiovascular Research), Partner Site Munich Heart Alliance, 80992 Munich, Germany

* Correspondence: oktay.tutarel@tum.de or otutarel@hotmail.com; Tel.: +49-89-1218-2729

check for

updates

Citation: Maurer, S.J.; Bauer, U.M.M.; Baumgartner, H.; Uebing, A.; Walther, C.; Tutarel, O. Acquired Comorbidities in Adults with Congenital Heart Disease: An Analysis of the German National Register for Congenital Heart Defects. J. Clin. Med. 2021, 10, 314. https://doi.org/10.3390/jcm10020314

Received: 30 November 2020 Accepted: 11 January 2021 Published: 16 January 2021

Publisher's Note: MDPI stays neutral with regard to jurisdictional clai$\mathrm{ms}$ in published maps and institutional affiliations.

Copyright: (C) 2021 by the authors. Licensee MDPI, Basel, Switzerland. This article is an open access article distributed under the terms and conditions of the Creative Commons Attribution (CC BY) license (https:// creativecommons.org/licenses/by/ $4.0 /)$.

\begin{abstract}
Background: As adults with congenital heart disease (ACHD) are getting older, acquired comorbidities play an important role in morbidity and mortality. Data regarding their prevalence in ACHD that are representative on a population level are not available. Methods: The German National Register for Congenital Heart Defects was screened for ACHD. Underlying congenital heart disease (CHD), patient demographics, previous interventional/surgical interventions, and comorbidities were retrieved. Patients $<40$ years of age were compared to those $\geq 40$ years. Results: A total of 4673 patients (mean age $33.6 \pm 10.7$ years, female $47.7 \%$ ) was included. At least one comorbidity was present in 2882 patients $(61.7 \%)$ altogether, and in $56.8 \%$ of patients below vs. $77.7 \%$ of patients over 40 years of age $(p<0.001)$. Number of comorbidities was higher in patients $\geq 40$ years $(2.1$ $\pm 2.1)$ than in patients $<40$ years $(1.2 \pm 1.5, p<0.001)$. On multivariable regression analysis, age and CHD complexity were significantly associated with the presence and number of comorbidities. Conclusions: At least one acquired comorbidity is present in approximately two-thirds of ACHD. Age and complexity of the CHD are significantly associated with the presence of comorbidities. These findings highlight the importance of addressing comorbidities in ACHD care to achieve optimal long-term outcomes.
\end{abstract}

Keywords: adult congenital heart disease; comorbidities; cardiovascular risk factors

\section{Introduction}

The number of adults with congenital heart disease (ACHD) is increasing [1]. Currently, it is estimated that adults account for two-thirds of patients with severe and other forms of congenital heart disease (CHD) in the general population [2]. These ACHD patients have to deal with residua and sequelae related to their CHD as well as acquired comorbidities, especially as they are aging [3]. These comorbidities are not just innocent bystanders but can determine the outcome of ACHD patients [4-7]. Representative data regarding the burden of comorbidities among ACHD patients are missing. Single-center studies reporting comorbidity rates in this population have been published [8]. These are 
mainly from tertiary referral centers and are limited by a small number of patients involved with the additional caveat of referral bias. Data from inpatient databases are available as well [9], but only include the sickest patients and therefore, provide only biased estimates of population-level comorbidity prevalence [3]. A population-based study from the UK included a large number of patients below the age of 18 years, making assumptions for ACHD patients difficult [10]. Recently, Agarwal et al. used data from a commercial claims database representing the claims of employees and dependents on a large employer health benefit program in the United States (US) [3]. However, as the authors of this study stated themselves, there might be a selection bias with such an approach, because individuals included had commercial insurance, and therefore are expected to be generally healthier and of a higher socioeconomic status [3]. Additionally, such an approach does not represent the general population of the US, because it excludes $51 \%$ of the general population with other types of insurance or no insurance at all [3].

Therefore, the aim of this study is to provide data regarding the prevalence of acquired comorbidities in ACHD patients that are representative on a population level.

\section{Material and Methods}

The German National Register for Congenital Heart Defects provides a nationwide database and is representative for CHD in Germany [11]. Its data are not primarily gathered by tertiary referral centers but rather represent a community-based population (see also Supplementary File S1). The main cardiac diagnosis, all concurrent cardiac anomalies, as well as all performed cardiac catheter and surgical interventions are recorded in a database using the International Pediatric and Congenital Cardiac Code (IPCCC) published by the International Society for Nomenclature of Pediatric and Congenital Heart Disease (ISNPCHD; http: / / www.ipccc.net). In addition, extracardiac diagnoses and acquired diseases are recorded using the ICD-10 code (International Statistical Classification of Diseases and Related Health Problems) published by the World Health Organization (WHO; http:/ / www.who.int/classifications/icd/en/). This information is extracted from medical reports by dedicated and trained staff.

The register was systematically screened in September 2017 for patients $\geq 18$ years of age starting in the year 2012 with a medical report present. The medical reports of eligible patients were last updated in March 2019. At the time of screening, 50,837 patients were included in the register, and out of these, 20,562 patients were $\geq 18$ years of age.

In addition to the underlying CHD, patient demographics and previous catheter interventional or surgical procedures were included in the analysis. Surgeries for cardiac pacemakers, internal cardiac defibrillators (ICD), and cardiac resynchronization devices (CRT) were registered separately. Diagnostic catheterizations were not included. Complexity of CHD was classified according to the Bethesda classification [12], which aims to group CHD in complex, moderate, and mild lesions. Mild lesions, for example, include isolated small ventricular septal defects, while Tetralogy of Fallot belongs to the group of CHD with moderate severity. CHD with great complexity include Eisenmenger syndrome, cyanotic CHD, and transposition of the great arteries, to name a few. Cardiac comorbidities like heart failure or arrhythmias, which can be sequelae of the CHD, were excluded, while coronary artery disease was included. Comorbidities were grouped using the ICD-10 code (Table A1, Appendix A).

Patients younger than 40 years of age were compared to those older than 40 years. Additionally, patients with a single-ventricle physiology (SVP) were compared to those with a biventricular CHD.

\subsection{Ethics and Patient Involvement}

The National Register was approved by the relevant Ethics Committee, and patients provided written informed consent for inclusion in the National Register and subsequent data use. Patients and public are continuously involved in all research projects, including design, conduct, and dissemination of the research from the National Register. 


\subsection{Data Availability Statement}

The data underlying this article cannot be shared publicly due to data privacy reasons and the according German regulations.

\subsection{Statistical Analysis}

Statistical analyses were performed using SPSS version 25 (IBM Corp., Armonk, NY, USA) and MedCalc Statistical Software version 19.2.1 (MedCalc Software Ltd., Ostend, Belgium). Continuous variables are presented as mean \pm standard deviation or median (interquartile range) depending on data distribution, whereas categorical variables are presented as number (percentage). Comparisons between groups were made using the Mann-Whitney U test or Student's $t$-test or Fisher's exact test or Chi-square test as appropriate. The relationship of age, complexity of heart disease (excluding those patients who could not be classified according to the Bethesda criteria [12]), and sex with the presence of comorbidities was assessed using multivariable logistic regression models. The relationship with number of comorbidities was assessed using multivariable negative binominal regression models. Multivariable negative binominal regression models were used instead of Poisson regression models because the number of comorbidities was overdispersed (i.e., conditional variance exceeded conditional mean). All tests were performed two-sided, and for all analyses, a $p$-value $<0.05$ was considered statistically significant.

\section{Results}

Overall, out of 50,837 CHD patients in the National Register at the time of database query, we identified 4673 patients (mean age $33.6 \pm 10.7$ years, $47.7 \%$ female) meeting the inclusion criteria. A mild defect was present in 1369 patients (29.3\%), a defect of moderate complexity in $1856(39.7 \%)$, and a severe defect in 1323 (28.3\%). In 125 patients (2.7\%), the $\mathrm{CHD}$ could not be classified according to the Bethesda criteria. More detailed information is presented in Table 1.

Table 1. Baseline characteristics.

\begin{tabular}{|c|c|c|c|c|}
\hline & $\begin{array}{c}\text { All } \\
(n=4673)\end{array}$ & $\begin{array}{l}<40 \text { Years } \\
(n=3584)\end{array}$ & $\begin{array}{l}\geq 40 \text { Years } \\
(n=1089)\end{array}$ & $p$ \\
\hline Mean age (years \pm SD) & $33.6 \pm 10.7$ & $28.7 \pm 5.2$ & $49.9 \pm 7.2$ & $<0.001$ \\
\hline Female & $2228(47.7 \%)$ & $1669(46.6 \%)$ & $559(51.3 \%)$ & $<0.01$ \\
\hline \multicolumn{5}{|l|}{$\begin{array}{l}\text { Bethesda classification of } \\
\text { CHD }\end{array}$} \\
\hline Mild & $1369(29.3 \%)$ & $1011(28.2 \%)$ & $358(32.9 \%)$ & \multirow{4}{*}{$<0.001$} \\
\hline Moderate & $1856(39.7 \%)$ & $1386(38.7 \%)$ & $470(43.2 \%)$ & \\
\hline Severe & $1323(28.3 \%)$ & $1091(30.4 \%)$ & $232(21.3 \%)$ & \\
\hline Other & $125(2.7 \%)$ & $96(2.7 \%)$ & $29(2.7 \%)$ & \\
\hline Genetic syndrome & $328(7.0 \%)$ & $300(8.4 \%)$ & $28(2.6 \%)$ & $<0.001$ \\
\hline Comorbidities $(\geq 1)$ & $2882(61.7 \%)$ & $2036(56.8 \%)$ & $846(77.7 \%)$ & $<0.001$ \\
\hline Cardiac surgery $(\geq 1)$ & $3841(82.2 \%)$ & $2988(83.4 \%)$ & $853(78.3 \%)$ & $<0.001$ \\
\hline Device surgery $(\geq 1)$ & $579(12.4 \%)$ & $372(10.4 \%)$ & $207(19.0 \%)$ & $<0.001$ \\
\hline $\begin{array}{c}\text { Interventional } \\
\text { catheterization }(\geq 1)\end{array}$ & $1530(32.7 \%)$ & $1188(33.1 \%)$ & $342(31.4 \%)$ & 0.283 \\
\hline EP study/ablation $(\geq 1)$ & $397(8.5 \%)$ & $199(5.6 \%)$ & $198(18.2 \%)$ & $<0.001$ \\
\hline
\end{tabular}

\subsection{Comorbidities}

At least one comorbidity was present in 2882 patients (61.7\%). According to the complexity of the CHD, at least one comorbidity was present in $55.3 \%$ of patients with a simple CHD, in $64.3 \%$ with a moderate CHD, and $63.7 \%$ with a complex CHD $(p<0.001)$. Female patients were as likely to have at least one comorbidity as male patients were $(62.9 \%$ vs. $60.5 \%, p=0.093)$. The most common comorbidities were endocrine and metabolic 
diseases (30.4\%), circulatory system disorders (28.2\%), and diseases of the nervous system $(11.5 \%)$ (Table 2).

Table 2. Prevalence of comorbidities, $n(\%)$.

\begin{tabular}{|c|c|c|c|c|}
\hline Comorbidities & $\begin{array}{c}\text { All } \\
(n=4673)\end{array}$ & $\begin{array}{l}<40 \text { Years } \\
(n=3584)\end{array}$ & $\begin{array}{l}\geq 40 \text { Years } \\
(n=1089)\end{array}$ & $p$ \\
\hline Infectious diseases (all) & $179(3.8)$ & $107(3.0)$ & $72(6.6)$ & $<0.001$ \\
\hline Viral hepatitis & $86(1.8)$ & $40(1.1)$ & $46(4.2)$ & $<0.001$ \\
\hline Neoplasms (all) & $102(2.2)$ & $54(1.5)$ & $48(4.4)$ & $<0.001$ \\
\hline Malignant neoplasm & $57(1.2)$ & $33(0.9)$ & $24(2.2)$ & $<0.01$ \\
\hline Benign neoplasm & $34(0.7)$ & $16(0.4)$ & $18(1.7)$ & $<0.001$ \\
\hline Uncertain/unknown behavior & $11(0.2)$ & $5(0.1)$ & $6(0.6)$ & 0.02 \\
\hline $\begin{array}{l}\text { Diseases of the blood/blood-forming } \\
\text { organs (all) }\end{array}$ & $243(5.2)$ & $159(4.4)$ & 84 (7.7) & $<0.001$ \\
\hline Anemias & $73(1.6)$ & $49(1.4)$ & $24(2.2)$ & 0.07 \\
\hline $\begin{array}{l}\text { Endocrine and metabolic diseases } \\
\text { (all) }\end{array}$ & 1419 (30.4) & $872(24.3)$ & $547(50.2)$ & $<0.001$ \\
\hline Obesity & $530(11.3)$ & $370(10.3)$ & $160(14.7)$ & $<0.001$ \\
\hline Disorders of thyroid gland & $422(9.0)$ & $284(7.9)$ & $138(12.7)$ & $<0.001$ \\
\hline Type 1 diabetes mellitus & $12(0.3)$ & $5(0.1)$ & $7(0.6)$ & $<0.01$ \\
\hline Diabetes mellitus (excluding Type 1) & $83(1.8)$ & $29(0.8)$ & $54(5.0)$ & $<0.001$ \\
\hline Hyperlipidemia & $144(3.1)$ & $39(1.1)$ & $105(9.6)$ & $<0.001$ \\
\hline Mental and behavioral disorders & $407(8.7)$ & $311(8.7)$ & $96(8.8)$ & 0.90 \\
\hline Diseases of the nervous system & $539(11.5)$ & $373(10.4)$ & $166(15.2)$ & $<0.001$ \\
\hline Diseases of the eye and adnexa & $98(2.1)$ & $65(1.8)$ & $33(3.0)$ & 0.02 \\
\hline $\begin{array}{c}\text { Diseases of the ear and mastoid } \\
\text { process }\end{array}$ & $72(1.5)$ & $49(1.4)$ & $23(2.1)$ & 0.09 \\
\hline $\begin{array}{c}\text { Diseases of the circulatory system } \\
\text { (all) }\end{array}$ & $1318(28.2)$ & $769(21.5)$ & $549(50.4)$ & $<0.001$ \\
\hline Hypertensive diseases & $730(15.6)$ & $412(11.5)$ & $318(29.2)$ & $<0.001$ \\
\hline Ischemic heart disease & $51(1.1)$ & $22(0.6)$ & $29(2.7)$ & $<0.001$ \\
\hline Cerebral infarction/stroke & $161(3.4)$ & $92(2.6)$ & $69(6.3)$ & $<0.001$ \\
\hline $\begin{array}{l}\text { Atherosclerosis precerebral/cerebral } \\
\text { arteries }\end{array}$ & $13(0.3)$ & $5(0.1)$ & $6(0.6)$ & 0.02 \\
\hline Atherosclerosis & $10(0.2)$ & $2(0.1)$ & $8(0.7)$ & $<0.001$ \\
\hline $\begin{array}{l}\text { Diseases of the respiratory system } \\
\text { (all) }\end{array}$ & $388(8.3)$ & $240(6.7)$ & 148 (13.6) & $<0.001$ \\
\hline COPD/asthma/chronic bronchitis & $176(3.8)$ & $95(2.7)$ & $81(7.4)$ & $<0.001$ \\
\hline Diseases of the digestive system & $311(6.7)$ & $185(5.2)$ & $126(11.6)$ & $<0.001$ \\
\hline Diseases of the skin & $123(2.6)$ & $97(2.7)$ & $26(2.4)$ & 0.67 \\
\hline $\begin{array}{l}\text { Diseases of the musculoskeletal } \\
\text { system and connective tissue }\end{array}$ & 344 (7.4) & $221(6.2)$ & $123(11.3)$ & $<0.001$ \\
\hline $\begin{array}{l}\text { Diseases of the genitourinary system } \\
\text { (all) }\end{array}$ & $247(5.3)$ & $151(4.2)$ & $96(8.8)$ & $<0.001$ \\
\hline $\begin{array}{c}\text { Glomerular disease, renal } \\
\text { tubulo-interstitial disease, renal } \\
\text { failure }\end{array}$ & $135(2.9)$ & $73(2.0)$ & $62(5.7)$ & $<0.001$ \\
\hline $\begin{array}{c}\text { Pregnancy, childbirth, and the } \\
\text { puerperium }\end{array}$ & $76(1.6)$ & $58(1.6)$ & $18(1.7)$ & 0.89 \\
\hline $\begin{array}{l}\text { Conditions originating in the } \\
\text { perinatal period }\end{array}$ & $18(0.4)$ & $16(0.4)$ & $2(0.2)$ & 0.28 \\
\hline $\begin{array}{c}\text { Congenital malformations, } \\
\text { deformation, and chromosomal } \\
\text { abnormalities }\end{array}$ & $390(8.3)$ & $335(9.3)$ & $55(5.1)$ & $<0.001$ \\
\hline Injury, poisoning & $156(3.3)$ & $98(2.7)$ & $58(5.3)$ & $<0.001$ \\
\hline $\begin{array}{c}\text { External causes of morbidity and } \\
\text { mortality }\end{array}$ & $17(0.4)$ & $13(0.4)$ & $4(0.4)$ & 1.00 \\
\hline
\end{tabular}


There was a statistically significant but weak correlation between the number of comorbidities and the number of cardiac surgeries (Spearman rank correlation coefficient $0.089, p<0.0001$ ) as well as the number of interventional catheterizations (Spearman rank correlation coefficient $0.079, p<0.0001$ ).

Coarctation of the aorta was the main CHD in 618 patients $(13.2 \%)$. Hypertension was more common in this group compared to the other patients $(48 \%$ vs. $10.8 \%, p<0.001)$. This was not the case for ischemic heart disease $(1.5 \%$ vs. $1.0 \%, p=0.35)$.

\subsection{Patients $<40$ Years of Age vs. Patients $\geq 40$ Years}

Altogether, 3584 patients (76.7\%) were below the age of 40 years, while 1089 patients $(23.3 \%)$ were 40 or older. There were more male $(53.4 \%)$ than female $(46.6 \%)$ patients in the age group $<40$ years, while there were more female $(51.3 \%)$ than male $(48.7 \%)$ patients in the age group $\geq 40$ years $(p<0.01)$. Severe CHD were more common in those below the age of 40 years (Table 1$)$. At least one comorbidity was present in $56.8 \%(n=2036)$ of patients below 40 years of age and in $77.7 \%(n=846)$ of patients over 40 years $(p<0.001)$. The number of comorbidities was also higher in patients $\geq 40$ years (mean number of comorbidities $2.1 \pm 2.1)$ than in patients $<40$ years $(1.2 \pm 1.5, p<0.001$; Figure 1$)$.

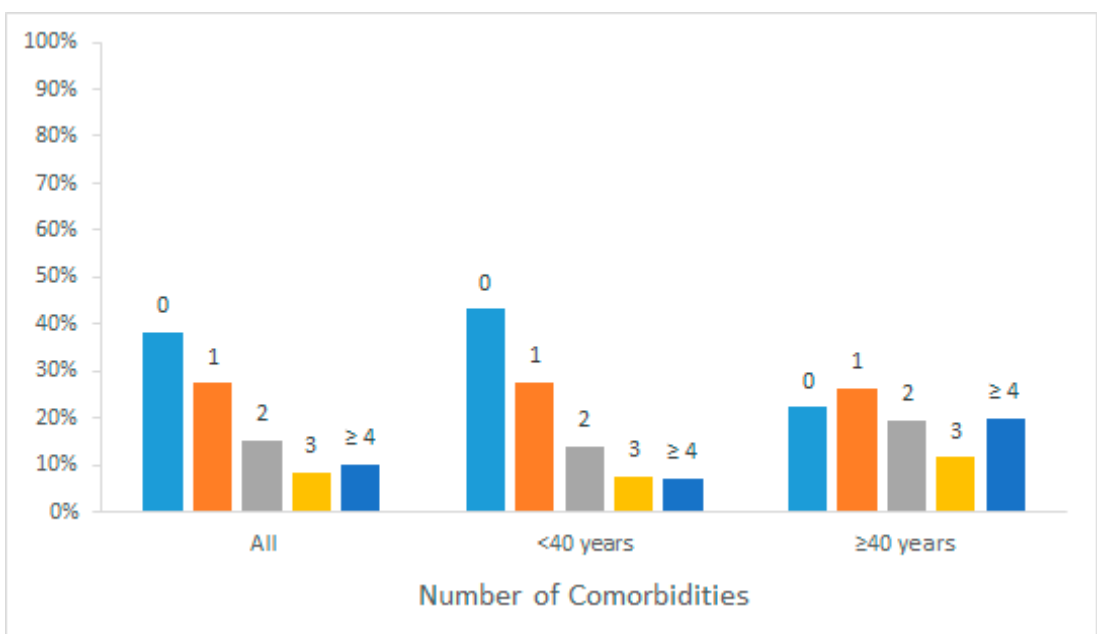

Figure 1. Number of comorbidities according to age group.

The most common acquired comorbidities in the age group $<40$ years were endocrine and metabolic diseases $(24.3 \%)$, circulatory system disorders $(21.5 \%)$, and diseases of the nervous system $(10.4 \%)$. In the age group $\geq 40$ years, diseases of the circulatory system were present in 549 patients (50.4\%), endocrine and metabolic diseases in 547 (50.2\%), and diseases of the nervous system in 166 (15.2\%). Cardiovascular risk factors like arterial hypertension, diabetes mellitus, and hyperlipidemia were more common in the older age group (Table 2).

\subsection{Single-Ventricle Physiology vs. Biventricular CHD}

Out of the 4673 patients, $347(7.4 \%)$ had a SVP. At least one comorbidity was present in 216 patients $(62.2 \%)$ with SVP and in 2666 (61.6\%) with a biventricular CHD $(p=0.82)$. Mean number of comorbidities was higher in SVP patients vs. biventricular CHD (1.7 \pm 2.2 vs. $1.4 \pm 1.7, p=0.032)$.

\subsection{Regression Analysis}

On multivariable logistic regression analysis, age and complexity of CHD were significantly associated with the presence of at least one comorbidity (Table 3). 
Table 3. Association between age, complexity of CHD, and gender with presence of at least one comorbidity.

\begin{tabular}{ccccc}
\hline & \multicolumn{2}{c}{ Univariate } & \multicolumn{2}{c}{ Multivariate } \\
\hline Variable & OR (95\% CI) & $p$ & OR (95\% CI) & $p$ \\
\hline Age (in years) & $1.05(1.04-1.06)$ & $<0.0001$ & $1.05(1.04-1.06)$ & $<0.0001$ \\
Male & $0.89(0.79-1.01)$ & 0.06 & & \\
Biventricular & $0.97(0.78-1.22)$ & 0.82 & & \\
CHD & $1.46(1.26-1.68)$ & $<0.0001$ & $1.53(1.32-1.77)$ & $<0.0001$ \\
Moderate CHD & $<0.0001$ & $1.57(1.34-1.84)$ & $<0.0001$ \\
Severe CHD & $1.42(1.22-1.66)$ & $<$ &
\end{tabular}

OR, odds ratio; $\mathrm{CHD}$, congenital heart disease.

Furthermore, age and complexity as well as SVP were significantly associated with the number of comorbidities (Table 4).

Table 4. Association between age, complexity of CHD, and gender with number of comorbidities.

\begin{tabular}{cccc}
\hline & Incidence Rate Ratio & $\begin{array}{c}\mathbf{9 5 \%} \text { Confidence } \\
\text { Interval }\end{array}$ & $p$ \\
\hline Age (in years) & 1.030 & $1.026-1.033$ & $<0.001$ \\
Male & 0.983 & $0.909-1.062$ & 0.658 \\
Moderate CHD & 1.245 & $1.132-1.370$ & $<0.001$ \\
Severe CHD & 1.351 & $1.210-1.509$ & $<0.001$ \\
Biventricular CHD & 0.793 & $0.677-0.928$ & 0.004 \\
\hline
\end{tabular}

CHD, congenital heart disease.

\section{Discussion}

In the current study, at least one acquired comorbidity is present in more than $60 \%$ of ACHD patients from the German National Register for Congenital Heart Defects. Age and complexity of the CHD are significantly associated with the presence of at least one comorbidity, as well as with the number of comorbidities. Additionally, SVP is associated with the number of comorbidities.

In a recent study based on data from a commercial database representing the claims of employees and dependents of a large employer health benefit program in the US, around $30 \%$ of ACHD patients between 18 and 40 years of age, and $58 \%$ of those older than 40 years, had a comorbidity [3]. These numbers are lower than those in our study, in which at least one comorbidity was present in $57 \%$ of patients below 40 years of age and in $78 \%$ of patients over 40 years. A reason for these differences could be that the patients in the US study were commercially insured. As the authors pointed out, these individuals are generally healthier and have a higher socioeconomic status than the general US population [3]. Therefore, the study by Agarwal et al. [3] might have underestimated the prevalence of comorbidities in ACHD patients by excluding sicker patients with a probably lower socioeconomic status. In this study, ACHD patients had a 1.73- and 1.47-fold higher risk for non-CHD associated cardiovascular and non-cardiovascular comorbidities, respectively, than controls without CHD [3]. In contrast, the current study is based in Germany, which has a universally accessible healthcare system. Therefore, the study population might be more representative of the general population than that studied by Agarwal et al., as well as those from several other studies $[9,10]$. Singh et al. studied extra-cardiac comorbidities in ACHD patients using the US National Inpatient Sample database [9]. While the number of patients without any comorbidity was not reported in this study, a high prevalence of different comorbidities was present in their study cohort [9]. Unfortunately, a comparison with our cohort is difficult. First, their population was much older (mean age 56.9 years) compared to our cohort (mean age 33.6 years) and also to the cohort of Agarwal et al. (mean age 36.8 years). Furthermore, it included only ACHD patients who were hospitalized and therefore, it might be biased by only including sicker patients who needed inpatient 
treatment [3,9]. A study from the UK that assessed comorbidities in CHD patients used a primary care database [10]. This approach has the advantage that the study cohort is derived from a large and nationally representative study population [10]. However, $46.9 \%$ of patients included in this study were below the age of 19 years, and the prevalence of comorbidities was reported only for the whole cohort [10]. Therefore, pediatric and adult cases were mixed up. Additionally, only selected comorbidities were reported. Therefore, the burden of comorbidities in ACHD patients might be underestimated in this study. Our study has the strengths of including all comorbidities reported in a large sample of only adult patients derived from a large nationwide database which is representative for CHD in Germany [11].

In the current study, most common acquired comorbidities were endocrine and metabolic diseases $(30.4 \%)$, circulatory system disorders $(28.2 \%)$, and diseases of the nervous system $(11.5 \%)$. In the older age group ( $>40$ years), the prevalence of most comorbidities increased, and circulatory disorders like hypertension, ischemic heart disease, and stroke became more important. Compared to the prevalence in the German general population, significant comorbidities like stroke and renal disease were much more common in our study cohort $[13,14]$. For example, in the German Health Interview and Examination Survey for Adults, a large representative study of the German population, the stroke prevalence in the age group $40-49$ years was $0.9 \%$ and for the age group 50-59 years it was $1.3 \%$ [14]. In contrast, it was $6.3 \%$ in our older age group, which had a mean age of 50 years. The higher incidence of stroke in ACHD patients has also been described in a Canadian study, in which the most important predictors of stroke were heart failure, diabetes mellitus, and a recent myocardial infarction [15]. Renal dysfunction is also an important predictor of outcome in ACHD patients, with a 3-fold higher mortality than normal in patients with moderate or severe renal dysfunction [4]. Cardiovascular risk factors like hypertensive disorders, diabetes mellitus, and hyperlipidemia contribute to the development of these comorbidities. These risk factors were present in a substantial number of patients in the current study, with approximately the same (diabetes mellitus) or even lower prevalence (hyperlipidemia) than in the general population [16,17]. In the younger age group (<40 years), hypertensive disorders were more common in our study compared to the general population, while their prevalence was similar to the general population in the older age group [18]. Our results are in accordance with the study by Agarwal et al., which reported a similar prevalence of hypertensive disorders and coronary artery disease as in our study, and an even higher prevalence for diabetes mellitus and hyperlipidemia compared to our cohort [3]. Another single-center study reported that even in a quite young cohort (median age 26 years) of ACHD patients, already $80 \%$ had at least one cardiovascular risk factor [19]. Accordingly, a Dutch study found an increased risk for coronary artery disease (CAD) in ACHD patients compared to the general population, with greater relative risk for those of younger age, women, and those with more severe CHD [20]. As ACHD patients are getting older, CAD becomes an important contributor to mortality [7]. Therefore, preventive measures are of the utmost importance, but unfortunately underutilized [21,22].

A limitation of this study is that comorbidities were retrieved from the diagnosis list in medical reports without access to laboratory data to assess the severity of the comorbidities like hyperlipidemia and endocrine disorders. Furthermore, outcome data like mortality were not available. Therefore, the impact of comorbidities on these outcome parameters could not be assessed. Additionally, the German National Register of Congenital Heart Defects only includes patients with CHD and no other groups of patients. Data on the German general population is unfortunately limited, because there is no general national register. We have tried to overcome this limitation by comparing our data to the data from other population-based German studies, which unfortunately used a different methodology, making comparison difficult. Therefore, we could not calculate standardized morbidity/mortality ratios. 


\section{Conclusions}

In conclusion, at least one acquired comorbidity is present in the majority of ACHD patients from the German National Register for Congenital Heart Defects. Age, complexity of the CHD, and SVP are significantly associated with the presence of comorbidities. These findings highlight the importance of preventive measures as well as early diagnosis and therapy of comorbidities in ACHD care to achieve optimal long-term outcomes.

Supplementary Materials: The following are available online at https:/ / www.mdpi.com/2077-038 3/10/2/314/s1, File S1: German Study Group Competence Network for Congenital Heart Defects.

Author Contributions: Conceptualization, S.J.M. and O.T.; methodology, S.J.M., U.M.M.B. and O.T.; formal analysis, O.T.; investigation, S.J.M., U.M.M.B. and O.T.; resources, U.M.M.B., H.B., A.U., C.W. and O.T.; data curation, U.M.M.B. and O.T.; writing—original draft preparation, S.J.M. and O.T.; writing-review and editing, all authors; project administration, O.T. All authors have read and agreed to the published version of the manuscript.

Funding: The German Competence Network for Congenital Heart Defects is funded by the Federal Ministry of Education and Research (BMBF), grant number 01GI0601 (until 2014), and by the German Centre for Cardiovascular Research (as of 2015).

Institutional Review Board Statement: The National Register was approved by the relevant Ethics Committee, and patients provided written informed consent for inclusion in the National Register and subsequent data use. Patients and public are continuously involved in all research projects, including design, conduct, and dissemination of the research from the National Register.

Informed Consent Statement: Patients provided written informed consent for inclusion in the National Register and subsequent data use.

Data Availability Statement: The data underlying this article cannot be shared publicly due to data privacy reasons and the according German regulations.

Conflicts of Interest: The authors declare no conflict of interest. The funders had no role in the design of the study; in the collection, analyses, or interpretation of data; in the writing of the manuscript; or in the decision to publish the results.

\section{Appendix A}

Table A1. Comorbidities according to ICD-10.

\begin{tabular}{cc}
\hline Comorbidities & ICD-10 Codes \\
\hline Infectious diseases & A00-B99 \\
Viral hepatitis & B15-B19 \\
Neoplasms & \\
Malignant neoplasm & C00-C97 \\
In situ neoplasm & D00-D09 \\
Benign neoplasm & D10-D36 \\
Uncertain/unknown behavior neoplasm & D37-D48 \\
Diseases of the blood/blood-forming organs & D65-D90 \\
Anemias & D50-D64 \\
Endocrine, nutritional, and metabolic diseases & E00-E90 \\
Disorders of thyroid gland & E00-E07 \\
Type 1 diabetes mellitus & E10 \\
Diabetes mellitus (excluding Type 1) & E11-E14 \\
Obesity & E66 \\
Hyperlipidemia & E78.0-E78.5, E78.8-E78.9 \\
Mental and behavioral disorders & F00-F99 \\
\hline
\end{tabular}


Table A1. Cont.

\begin{tabular}{cc}
\hline Comorbidities & ICD-10 Codes \\
\hline Diseases of the nervous system & G00-G99 \\
Diseases of the eye and adnexa & H00-H59 \\
Diseases of the ear and mastoid process & H60-H95 \\
Diseases of the circulatory system & I00-I99 excl. I27.28-I27.9, I30-I39, I42-I52, I71 \\
Hypertensive diseases & I10-I15 \\
Ischemic heart disease & I20-I25 \\
Cerebral infarction/stroke & I63-I64 \\
Atherosclerosis & I65-I66, I67.2 \\
Atherosclerosis precerebral/cerebral arteries & I70 \\
Diseases of the respiratory system & J00-J99 \\
COPD/asthma/chronic bronchitis & J40-J47 \\
Diseases of the digestive system & L00-K93 \\
Diseases of the skin & M00-M99 \\
Diseases of the musculoskeletal system and & N20-N99 \\
connective tissue & N00-N19 \\
Diseases of the genitourinary system & O00-O99 \\
Glomerular disease, renal tubulo-interstitial & P00-P96 \\
disease, renal failure & S00-T98 excl. T80-T88 \\
Pregnancy, childbirth, and the puerperium & V01-Y84 \\
Conditions originating in the perinatal period & Q00-Q99 excl. Q20-Q28 \\
Congenital malformations, deformation, and & Injury, poisoning
\end{tabular}

\section{References}

1. Warnes, C.A. Adult congenital heart disease: The challenges of a lifetime. Eur Heart J. 2017, 38, 2041-2047. [CrossRef] [PubMed]

2. Marelli, A.J.; Ionescu-Ittu, R.; Mackie, A.S.; Guo, L.; Dendukuri, N.; Kaouache, M. Lifetime prevalence of congenital heart disease in the general population from 2000 to 2010. Circulation 2014, 130, 749-756. [CrossRef] [PubMed]

3. Agarwal, A.; Thombley, R.; Broberg, C.S.; Harris, I.S.; Foster, E.; Mahadevan, V.S.; John, A.; Vittinghoff, E.; Marcus, G.M.; Dudley, R.A. Age- and Lesion-Related Comorbidity Burden Among US Adults with Congenital Heart Disease: A Population-Based Study. J. Am. Heart Assoc. 2019, 8, e013450. [CrossRef] [PubMed]

4. Dimopoulos, K.; Diller, G.P.; Koltsida, E.; Pijuan-Domenech, A.; Papadopoulou, S.A.; Babu-Narayan, S.V.; Salukhe, T.V.; Piepoli, M.F.; Poole-Wilson, P.A.; Best, N.; et al. Prevalence, predictors, and prognostic value of renal dysfunction in adults with congenital heart disease. Circulation 2008, 117, 2320-2328. [CrossRef] [PubMed]

5. Alonso-Gonzalez, R.; Borgia, F.; Diller, G.P.; Inuzuka, R.; Kempny, A.; Martinez-Naharro, A.; Tutarel, O.; Marino, P.; Wustmann, K.; Charalambides, M.; et al. Abnormal lung function in adults with congenital heart disease: Prevalence, relation to cardiac anatomy, and association with survival. Circulation 2013, 127, 882-890. [CrossRef] [PubMed]

6. Afilalo, J.; Therrien, J.; Pilote, L.; Ionescu-Ittu, R.; Martucci, G.; Marelli, A.J. Geriatric congenital heart disease: Burden of disease and predictors of mortality. J. Am. Coll. Cardiol. 2011, 58, 1509-1515. [CrossRef]

7. Tutarel, O.; Kempny, A.; Alonso-Gonzalez, R.; Jabbour, R.; Li, W.; Uebing, A.; Dimopoulos, K.; Swan, L.; Gatzoulis, M.A.; Diller, G.P. Congenital heart disease beyond the age of 60: Emergence of a new population with high resource utilization, high morbidity, and high mortality. Eur. Heart J. 2014, 35, 725-732. [CrossRef] [PubMed]

8. Deen, J.F.; Krieger, E.V.; Slee, A.E.; Arslan, A.; Arterburn, D.; Stout, K.K.; Portman, M.A. Metabolic Syndrome in Adults with Congenital Heart Disease. J. Am. Heart Assoc. 2016, 5. [CrossRef]

9. Singh, S.; Desai, R.; Fong, H.K.; Sadolikar, A.; Samani, S.; Goyal, H. Extra-cardiac comorbidities or complications in adults with congenital heart disease: A nationwide inpatient experience in the United States. Cardiovasc. Diagn. Ther. 2018, 8, 814-819. [CrossRef]

10. Billett, J.; Cowie, M.R.; Gatzoulis, M.A.; Vonder Muhll, I.F.; Majeed, A. Comorbidity, healthcare utilisation and process of care measures in patients with congenital heart disease in the UK: Cross-sectional, population-based study with case-control analysis. Heart 2008, 94, 1194-1199. [CrossRef]

11. Helm, P.C.; Koerten, M.A.; Abdul-Khaliq, H.; Baumgartner, H.; Kececioglu, D.; Bauer, U.M. Representativeness of the German National Register for Congenital Heart Defects: A clinically oriented analysis. Cardiol. Young 2016, 26, 921-926. [CrossRef] [PubMed]

12. Warnes, C.A.; Liberthson, R.; Danielson, G.K.; Dore, A.; Harris, L.; Hoffman, J.I.; Somerville, J.; Williams, R.G.; Webb, G.D. Task force 1: The changing profile of congenital heart disease in adult life. J. Am. Coll. Cardiol. 2001, 37, 1170-1175. [CrossRef] 
13. Girndt, M.; Trocchi, P.; Scheidt-Nave, C.; Markau, S.; Stang, A. The Prevalence of Renal Failure. Results from the German Health Interview and Examination Survey for Adults, 2008-2011 (DEGS1). Dtsch. Arztebl. Int. 2016, 113, 85-91. [CrossRef] [PubMed]

14. Busch, M.A.; Schienkiewitz, A.; Nowossadeck, E.; Gosswald, A. Prevalence of stroke in adults aged 40 to 79 years in Germany: Results of the German Health Interview and Examination Survey for Adults (DEGS1). Bundesgesundheitsblatt Gesundh. Gesundh. 2013, 56, 656-660. [CrossRef] [PubMed]

15. Lanz, J.; Brophy, J.M.; Therrien, J.; Kaouache, M.; Guo, L.; Marelli, A.J. Stroke in Adults With Congenital Heart Disease: Incidence, Cumulative Risk, and Predictors. Circulation 2015, 132, 2385-2394. [CrossRef]

16. Heidemann, C.; Du, Y.; Schubert, I.; Rathmann, W.; Scheidt-Nave, C. Prevalence and temporal trend of known diabetes mellitus: Results of the German Health Interview and Examination Survey for Adults (DEGS1). Bundesgesundheitsblatt Gesundh. Gesundh. 2013, 56, 668-677. [CrossRef]

17. Scheidt-Nave, C.; Du, Y.; Knopf, H.; Schienkiewitz, A.; Ziese, T.; Nowossadeck, E.; Gosswald, A.; Busch, M.A. Prevalence of dyslipidemia among adults in Germany: Results of the German Health Interview and Examination Survey for Adults (DEGS 1). Bundesgesundheitsblatt Gesundh. Gesundh. 2013, 56, 661-667. [CrossRef]

18. Neuhauser, H.; Thamm, M.; Ellert, U. Blood pressure in Germany 2008-2011: Results of the German Health Interview and Examination Survey for Adults (DEGS1). Bundesgesundheitsblatt Gesundh. Gesundh. 2013, 56, 795-801. [CrossRef]

19. Moons, P.; Van Deyk, K.; Dedroog, D.; Troost, E.; Budts, W. Prevalence of cardiovascular risk factors in adults with congenital heart disease. Eur. J. Cardiovasc. Prev. Rehabil. 2006, 13, 612-616. [CrossRef]

20. Kuijpers, J.M.; Vaartjes, I.; Bokma, J.P.; van Melle, J.P.; Sieswerda, G.T.; Konings, T.C.; Boo, M.B.; van der Bilt, I.; Voogel, B.; Zwinderman, A.H.; et al. Risk of coronary artery disease in adults with congenital heart disease: A comparison with the general population. Int. J. Cardiol. 2019. [CrossRef]

21. Bauer, U.M.M.; Korten, M.A.; Diller, G.P.; Helm, P.; Baumgartner, H.; Ewert, P.; Tutarel, O. Cardiovascular risk factors in adults with congenital heart defects-Recognised but not treated? An analysis of the German National Register for Congenital Heart Defects. Int. J. Cardiol. 2019, 277, 79-84. [CrossRef] [PubMed]

22. Flannery, L.D.; Fahed, A.C.; DeFaria Yeh, D.; Youniss, M.A.; Barinsky, G.L.; Stefanescu Schmidt, A.C.; Benavidez, O.J.; Meigs, J.B.; Bhatt, A.B. Frequency of Guideline-Based Statin Therapy in Adults with Congenital Heart Disease. Am. J. Cardiol. 2018, 121, 485-490. [CrossRef] [PubMed] 